\title{
ABSORBING PROPERTIES AND OPTIMIZATION OF Ni POWDER/M-GLASS FIBER REINFORCED EPOXY COMPOSITE PANELS
}

\author{
XIAOMIN LI \\ School of Materials Science and Engineering, Nanchang University, Nanchang, 330031, P. R. China \\ gllixiaomin@sina.com \\ ZHENGHOU ZHU* \\ School of Materials Science and Engineering, Nanchang University, Nanchang, 330031, P. R. China \\ *Corresponding author: z00708@sina.com
}

\section{HUI SONG}

School of Materials Science and Engineering, Nanchang University, Nanchang, 330031, P. R. China ncsh01@126.com

\section{XUEJIAO XU}

School of Materials Science and Engineering, Nanchang University, Nanchang, 330031, P. R. China xxj198712@163.com

\section{ZHIBIN LIU}

School of Materials Science and Engineering, Nanchang University, Nanchang, 330031, P. R. China liuyinc@163.com

\begin{abstract}
In this paper, $\mathrm{Ni}$ powder/M-glass fiber reinforced epoxy composite panels with different $\mathrm{Ni}$ powders were prepared by mould pressing method, of which the ultrafine Ni powder is prepared by the liquid reduction method. The waveguide method can be used to measure the electromagnetic parameters of the samples in the frequency ranged from $8.2 \mathrm{GHz}$ to $18 \mathrm{GHz}$. The results show that Ni powders distributed evenly during the M-glass fibers reinforced epoxy layers. The main absorbing mechanism of composite panels is magnetic loss. The absorbing properties of samples increase with the adding of Ni powder contents and the thickness of panels. Based on the theory of the transmission line, the optimization design of Ni powder/ M-glass fiber reinforced epoxy composite has been calculated. When the whole thickness of the composite panels is $4.6 \mathrm{~mm}$ excepting the Al plate thickness with the absorbing layer of Ni powder/ M-glass fiber reinforced epoxy of $1 \mathrm{~mm}$, the whole absorbing properties improve gradually with the increase of frequency ranged from $8.2 \mathrm{GHz}$ to $18 \mathrm{GHz}$ and the absolute value of the reflection coefficient $\mathrm{R}$ is above $10 \mathrm{~dB}$.
\end{abstract}

Keywords: Absorbing properties; optimization; Ni powder; epoxy; composite panel.

\section{Introduction}

In the national defense fields, stealth technology is always one of the key technologies of weapon equipment. In order to reduce the radar cross section (RCS) of weapon 
equipment, such as aircraft, missile, tanks, more and more people focus their attentions on the improvement of radar absorbing materials (RAM) except for the object shape design. So the RAM with "thin, light, wide, strong" characteristics is becoming one of the important research aspects of modern stealth technology. ${ }^{1-3}$ Electromagnetic parameters are the essential factors to the absorbing materials. Therefore, it is necessary to select proper absorbing materials with reasonable electromagnetic parameters and optimize the absorbing properties in order to improve the comprehensive performance of the absorbing materials.

\section{Experimental}

The superfine Ni powder is used as the absorbing material, which is prepared by the liquid reduction method with grain size of $5 \sim 15 \mu \mathrm{m}$. Then the surface of the Ni powder is coating a layer of $\mathrm{SiO}_{2}(1 \sim 10 \mu \mathrm{m})$ by the sol-gel method as a kind of surface modification. The epoxy glue, which can be obtained by mixing E-51, thinner, coupling agent, triethylene tetramine (TETB) and different contents of the Ni powder, is spread evenly on the surface of the M-glass fiber by mould pressing method. The serial numbers of sample are shown as follows. Then the absorbing properties of samples were optimized by the software of multilayer radar wave reflection coefficient which designed by our team. The sample numbers are shown in Table 1.

Table 1. Serial numbers of sample with different contents of Ni powder

\begin{tabular}{ll}
\hline Sample number & the mass ratio of epoxy: Ni powder \\
\hline E-51 & Pure epoxy \\
B1 & $1: 0.3$ \\
B2 & $1: 0.5$ \\
B3 & $1: 0.7$ \\
\hline
\end{tabular}

The phase analysis of $\mathrm{Ni}$ powder is tested by X-ray diffraction with a model of Bruker D8 Focus. The metallographic analysis is tested by the MEF3 model metallographic microscope and the electromagnetic parameters of the composite panels are tested by the waveguide method with the testing frequency ranged from $8.2 \mathrm{GHz}$ to $18 \mathrm{GHz}$.

\section{Results and discussion}

\subsection{XRD analysis}

Fig. 1 shows the XRD pattern of Ni powder prepared by the liquid reduction method. It is clearly to see that there are three sharp diffraction peaks at around $44^{\circ}, 52^{\circ}$ and $77^{\circ}$ respectively, which are the characteristic peaks of $\mathrm{Ni}$ and the other impurity peaks such as $\mathrm{NiO}$ or $\mathrm{Ni}(\mathrm{OH})_{2}$ are not appeared. It also proves that the state of $\mathrm{Ni}$ powder is $\mathrm{FCC}$ crystalline structure. 


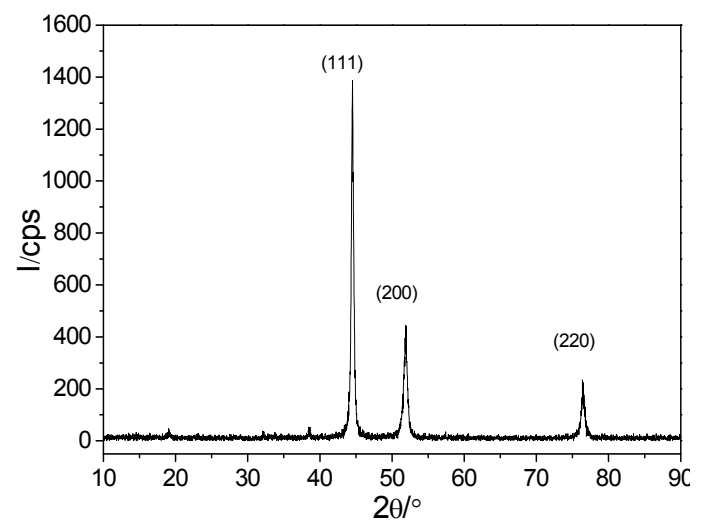

Fig. 1. XRD pattern of the Ni powder

\subsection{Metallographic analysis}

Fig. 2 shows the metallurgical figures of the composite panels, which is observed by metallographic microscope. As can be seen from Fig. 2 (a) and Fig. 2 (b) with different enlargement scales, Ni powder spread evenly between the layers of M-glass fibers. Such structure is comparatively coincides with our expectation. Furthermore, it also indicates that the selection of mould pressing method is suitable for preparing the composite panels.
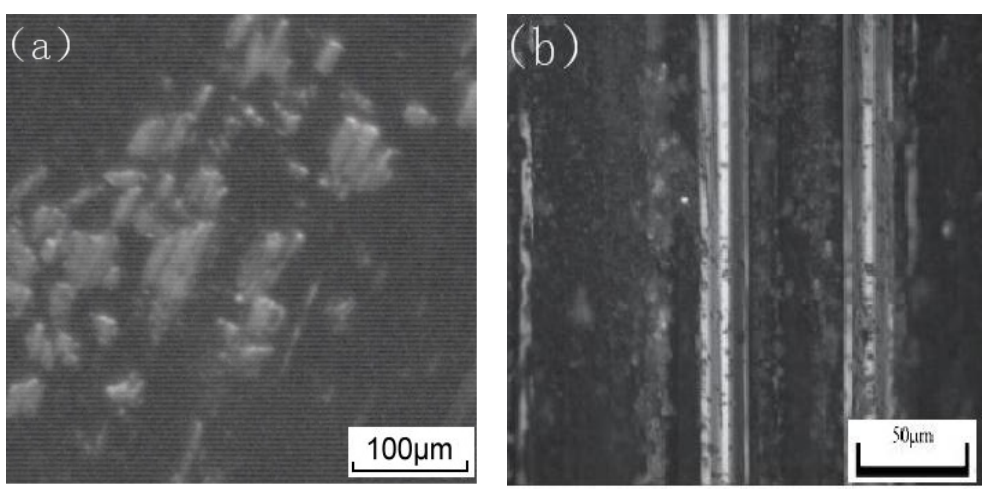

Fig. 2. The metallurgical figures of sample

\subsection{Electromagnetic parameters of the composite panels}

Generally speaking, to the absorbing materials with excellent absorbing properties, it should be satisfied with two conditions: firstly, the electromagnetic matching between the materials and the air should be as good as possible to make sure most of electromagnetic waves can get access to inside of the material. Secondly, once the electromagnetic waves getting into the inside, the electromagnetic wave should be attenuated rapidly, namely, the electromagnetic loss of the materials should be as large as possible. ${ }^{4}$ 

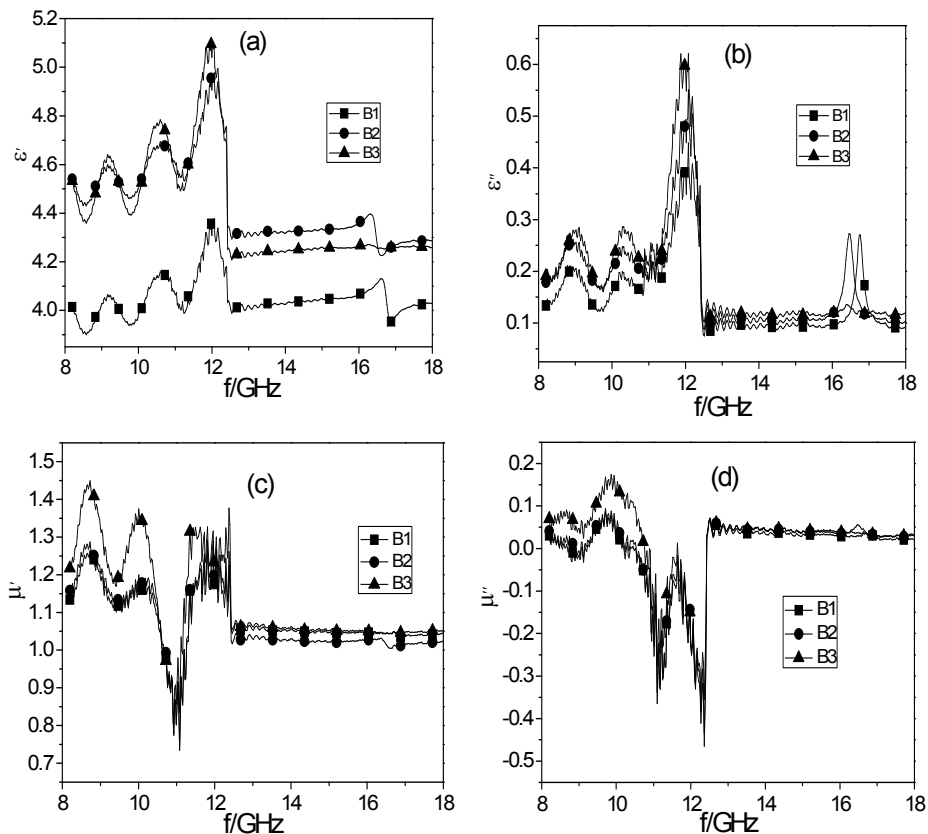

Fig. 3. Electromagnetic parameters of composite panels with different Ni powder contents
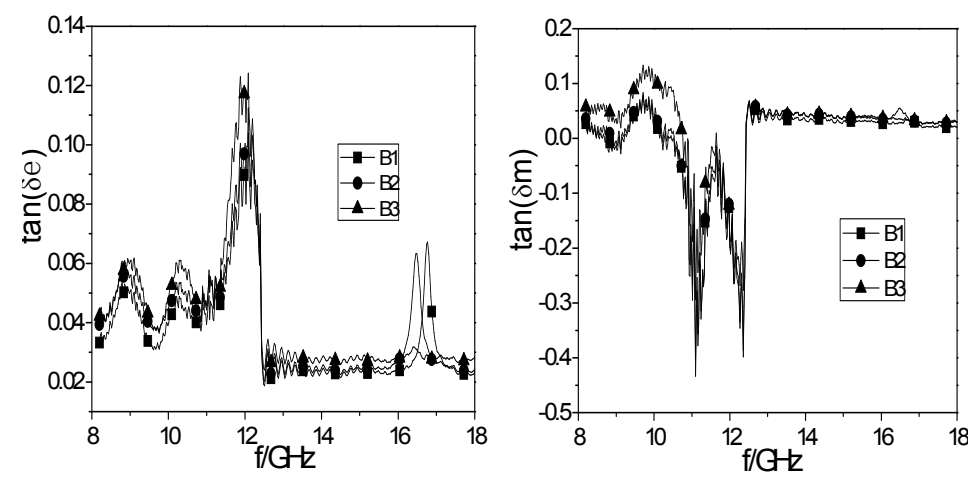

Fig. 4. Electromagnetic loss tangent curves of composite panels with different Ni powder contents

The electromagnetic parameters curves and the electromagnetic loss tangent curves of composite panels with different Ni powder contents are shown in Fig. 3 from (a) to (d) and Fig. 4 respectively. From the curves, we can see that the magnetic and dielectric losses of the composite panels increase with the rising of the amount of the powders and the main absorbing mechanism of composite panels is magnetic loss. In addition, with the adding of Ni powder, the electromagnetic matching between the composite panels and air become worse and the absorbing properties of the composites improve with the increase of the absorbing powders contents. When the frequency is about $11 \mathrm{GHz}$, the magnetic loss tangent value reaches minimum of -0.4 and the dielectric loss tangent value reaches maximum at around $12 \mathrm{GHz}$ with the value of 0.12 . It indicates that the main absorbing mechanism of composite panels is magnetic loss. 


\subsection{The surface reflection coefficient of the composite panels}

It is well known that the reflection and refraction will happen simultaneously when electromagnetic wave shoots on the surface of samples. The part of reflection is called surface reflection. Generally speaking, the smaller of the surface reflection coefficient demonstrate the better of the electromagnetic matching of the samples with the air. Fig. 5 shows the curves of the reflection coefficient at the surface of the composite panels, we can see from Fig. 5 that the absolute values of the reflection coefficient of the composite panels at the surface of the panels become smaller with the adding of the amount of $\mathrm{Ni}$ powders, which also means the electromagnetic matching performances between the sample and the air become worse.

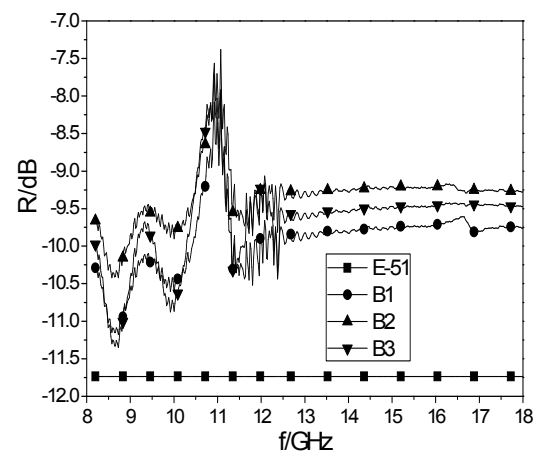

Fig. 5. The curves of the surface reflection coefficient

\subsection{Absorbing Property Optimization of Composites}

M-glass fiber reinforced epoxy composite panels have great transparent properties to waves. According to measurement, its surface reflection coefficient is relatively lower than that adding absorbing powder with the value of $-11.7 \mathrm{~dB}$. When we combine the Mglass fiber reinforced epoxy composite panels with the amorphous powders/ M-glass fiber reinforced epoxy composite panels with gradient layer structure served as the wave transparent layers, while the $\mathrm{Al}$ layers are considered as the layers of total reflection.

Based on the theory of the transmission line, the optimization design of Ni powder/ M-glass fiber reinforced epoxy composite has been calculated, and the suitable thickness ranges of B1, B2 and B3 are shown in Table 2.

Table 2. Thickness of absorbing layers at different composite panels

\begin{tabular}{llll}
\hline Absorbing layer number & B1 & B2 & B3 \\
\hline Thickness of absorbing layer $/ \mathrm{mm}$ & $1.2 \sim 2.7$ & $1.0 \sim 2.4$ & $0.7 \sim 2.8$ \\
\hline The whole thickness of composites $/ \mathrm{mm}$ & 4.6 & 4.6 & 4.6 \\
\hline
\end{tabular}




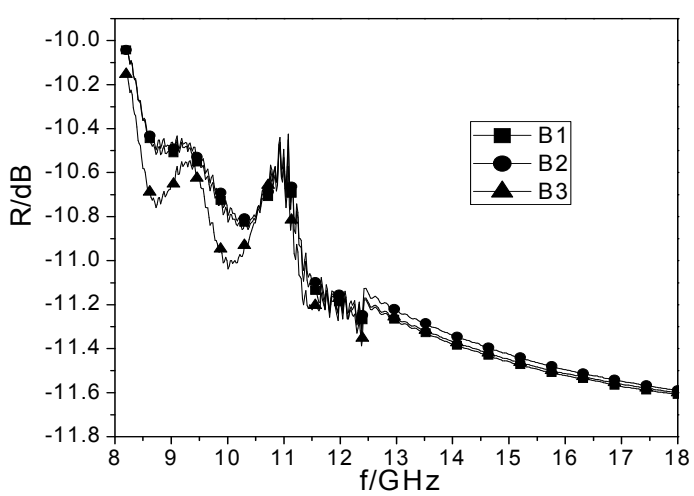

Fig. 6. The absorbing properties curves of composite panels

Fig. 6 shows the absorbing properties curves of composites. We can see from the curves that when the whole thickness of the composite panels is $4.6 \mathrm{~mm}$ excepting the $\mathrm{Al}$ plate thickness with the absorbing layer of Ni powder/ M-glass fiber reinforced epoxy with $1 \mathrm{~mm}$ thickness, the whole absorbing properties improve gradually with the increase of frequency ranged from $8.2 \mathrm{GHz}$ to $18 \mathrm{GHz}$ and the absolute value of the reflection coefficient $\mathrm{R}$ is above $10 \mathrm{~dB}$ in $8.2 \mathrm{GHz} 18 \mathrm{GHz}$, which has a practical application value in the national defense fields.

\section{Conclusions}

The Ni powder/ M-glass fiber reinforced epoxy composite panels were prepared successfully by mould pressing method. Ni powders distribute evenly during the layers of the composite panels. The magnetic and dielectric losses of the composite panels increase with the rising of powders and the main absorbing mechanism is magnetic loss. With the addition of Ni powders, the electromagnetic matching between the composite panels and air become worse and the absorbing properties of the composites improve with the increase of Ni powders contents. Through calculation, the whole absorbing properties improve gradually at the frequency ranged from $8.2 \mathrm{GHz}$ to $18 \mathrm{GHz}$ and the absolute value of the reflection coefficient $\mathrm{R}$ is above $10 \mathrm{~dB}$ at the whole frequency range.

\section{Acknowledgments}

This work was financially supported by National Natural Science Foundation of China (60961001), Advance Research of National “973” Program of China (2010CB635112) and NSFC United Fund (11076016).

\section{References}

1. S. C. Wang, K. G. Neoh and E. T. Kang, J. Mater. Chem. 17, 2775 (2007).

2. S. M. Abbas, A. K. Dixit and R. Chatterjee, J. Magn. Mater. 309, 20(2007).

3. S. Q. Zhang, C. G. Huang and Z. Y. Zhou, Mater. Sci. Eng. B 90, 38(2002).

4. M. X. Chen, Y. Zhu and Y.B. Pan, Mater. Design 32, 3013(2011). 